DOI: 10.20472/IAC.2019.049.009

\author{
ANTONIJA CAVCIC \\ Teikyo University of Science, Tokyo, Japan
}

\title{
EVALUATING POLICY AND PRACTICALITY IN TOKYO METROPOLITAN GOVERNMENT'S PRE-OLYMPIC ENGLISH LANGUAGE PEDAGOGY
}

\begin{abstract}
:
In a context of increased internationalization and in preparation for the 2020 Olympics in Tokyo, in 2014 Japan's Ministry of Education, Culture, Sports, Science and Technology (MEXT) released the "English Education Reform Plan" which aimed to implement English education reform through elementary, lower and upper secondary schools. A year later, the Tokyo Metropolitan Board of Education (TMBOE) distributed the Welcome to Tokyo series of textbooks to all students at grade five and above at public elementary schools in the Tokyo Metropolitan area. The general intention was to bolster young students' English skills. However, rather than focusing on language acquisition, critics have revealed that two main discourses are repeated throughout the policy documents issued by both MEXT and TMBOE. Namely, "developing human resources" and "nurturing Japanese identity." Hiroshi Miyashita has argued that "careful attention should be paid to these measures because they have potential to lead students to exclusivism or even nationalism without extra care" (Miyashita, 2017). In regards to the subtext and efficacy of these policies, this paper examines the Welcome to Tokyo series. By means of discourse analysis and taking into consideration content, lexical range, representation of race and gender, word frequency and structure, I question the text's overall suitability for effective English language acquisition in an increasingly internationalized environment. To conclude, a brief summary offering suggestions for improvement and advice for educators in this context will be provided.
\end{abstract}

\section{Keywords:}

education, education data, school, education quality

JEL Classification: 120, 121, 129 


\section{Introduction}

In 2016, Japan's Ministry of Education, Culture, Sports, Science and Technology (MEXT) released their newly revised education policy regarding English education. Naturally, the primary goal is to nurture basic English skills and students' communicative abilities, but it also stipulates that educators need to enrich educational content in relation to "nurturing the individual sense of Japanese identity" (MEXT, 2016). In their project on a pre-Olympics English preparatory course which involved learning how to introduce one's culture to "foreign visitors", Lange, Gorshov and Flanagan also stressed that "English language remains at the forefront of the Japanese government's plans for Japan to compete in the global economy and strengthen and promote its national identity to the international community" (2017, p.273). In regards to the international expansion of businesses, this seems like a reasonable suggestion. However, one might question the emphasis placed on nurturing and further promoting one's national identity when discussing language acquisition. Communication, needless to say, is a two-way street. That is, part of the process of internationalization arguably involves fostering a sense of understanding of (and interest in) other cultures as well as communication based on interaction and negotiation rather than unidirectional output. As Mike Byram reinforces in his work on intercultural communicative competence, if learning is seen as a "simple relationship" between the learner's world and the foreign language, students probably will not have the "experience of otherness" which is ideally a major part of language learning at school (Byram, 2008, p.77-8).

Nevertheless, it is in response to this context and policy that the Welcome to Tokyo series was planned and released. Colorful, packed full of images and complete with DVDs, the seemingly user-friendly Welcome to Tokyo series was planned and produced by NHK, but published by the Tokyo Metropolitan Board of Education (TMBOE) in 2016. The entire project was supervised by Sophia University's Yoshida Kensaku and Rikkyo University's Matsumoto Shigeru was the editorin-chief. Interestingly, all members on the editorial committee were Japanese. In terms of the written content, the only non-Japanese contributors were responsible for supervising the accuracy and quality of the English text. So far, there are three levels in the series: elementary (for students in grades five and six in elementary school); basic (for junior high school students); and intermediate (for high school students). As for the basic contents outlined by the TMBOE, refer to website's blurbs presented in Figure 1. 


\section{Figure 1: Blurbs in Welcome to Tokyo}

Blurbs in Welcome to Tokyo (TMBOE, 2018)

\begin{tabular}{|l|l|}
\hline Level & Blurb \\
\hline Elementary & $\begin{array}{l}\text { Nine original characters introduce noteworthy and appealing aspects unique to } \\
\text { Tokyo. Tourist attractions, special products and events in Tokyo's } 62 \text { municipalities } \\
\text { are featured in picture cards that can be used for activities and projects } \\
\text { (investigative learning) dealt with in the teaching materials. }\end{array}$ \\
\hline Basic & $\begin{array}{l}\text { High school student Sakura visits all sorts of places with Robin, a homestay } \\
\text { student staying at her house. A drama of discovery showcasing the charm of Tokyo, } \\
\text { a city both old and new. Sakura's neighbor Ricky has a segment introducing parts } \\
\text { of Tokyo. }\end{array}$ \\
\hline Intermediate & $\begin{array}{l}\text { The story of high school student Kana and video journalist Emma going around } \\
\text { collecting data on different parts of Tokyo. Through the eyes of these two, you gain } \\
\text { deep insight into Tokyo from several angles. You can also see "Emma's Report," a } \\
\text { documentary Emma makes based on the data they collect. }\end{array}$ \\
\hline
\end{tabular}

Source: Tokyo Metropolitan Board of Education, 2018.

Evidently, from simply skimming the contents of the series, it is clear that there is a distinct emphasis on "introducing" Tokyo. Thus, to investigate whether and to what extent the texts actually foster effective language learning through meaningful interaction, this paper will proceed by considered the level appropriateness, and more importantly, the content.

\section{Analysis: Level Appropriateness}

Since this analysis of Welcome to Tokyo primarily concerns the level appropriateness and relevance of content, the texts have only been evaluated in terms of these factors. Firstly, let us consider the level appropriateness. In regards to the amount of content of each level, there are nine units for the elementary course, 12 units for the basic course and 14 units for the intermediate course. While there is about a semester's worth of material, the books are not the officially mandated textbooks intended for English courses. In that respect, it is best to consider them supplementary materials which can be used over the course of a year. However, in terms of suitability for students and instructors whose English competence levels may vary wildly, they might pose a problem. As Hirosaki University's Megumi Tada has suggested, the lack of teachers who can effectively use the language makes learning English so difficult in Japan (Pickles, 2017). For instance, in 2017 the Kyoto Board of Education asked 74 middle school teachers in the prefecture to take the TOEIC test. Only 16 teachers reached over the 730 points, while 14 teachers could not even reach a score of 500 and the lowest score was 280-the level of some of their students (Mainichi, 2017). These linguistic gaps not only need to be addressed, but they ought to be taken into account when creating official textbooks and teaching materials.

Unfortunately, the production team behind the Welcome to Tokyo series either ignored or overestimated the average English language competency levels of the users of the text. This is 
reflected both in the structure and the lexical range of the texts. For example, the structure of the texts may seem easy on the eye given that roughly $40 \%$ of the text appears to be images or white space (roughly $85 \%$ at the elementary level), but there are fundamental flaws in the components of each unit. For example, in the basic-level textbook, each unit begins with a warm-up page, followed by a function page and an activity page. These are fairly simple and in terms of scaffolding, it is a reasonable approach. However, the abrupt transition into the subsequent textdense components (namely, the "Tokyo Information" page, the project page and the drama script) is quite challenging. For instance, the "How to enjoy sushi" excerpt in the basic-level textbook has a Flesch ease of reading score of about 70 and the drama script of the same unit has a score of 62 (both of which are ideal for native speakers of English aged 13 to 15). This is arguably quite challenging for JHS-level learners.

Furthermore, there is very little in the way of scaffolding on the "Project pages". Sometimes students are expected to "Make a presentation to the class" without a basic template to work with (aside from an example that might not be adaptable). As a result, it requires extra preparation on part of the instructor and added stress to learners in a large class who might not be able to receive attention. In a similar fashion, the intermediate-level textbook has some structural flaws. Its three components include: a video with three activities, two-page-long reports complete with comprehension questions and speech writing activities (also without adaptable templates), and a drama script (ranging from 40 to 50 lines and with no particular function aside from supplementing the DVD). In regard to ease of reading, some reports, for instance the "Edo-komon" excerpt, had a Flesch score of 58 (grade 10 to 12 in the United States). Once again, this might prove challenging for some learners. Part of the problem, I believe, is the lexical range. For instance, 'kelp', 'humility', 'deferential', 'virtue', 'punchline', 'base-isolation structure', 'discrimination', 'fundamental principle', 'deities', 'chemical reaction', 'infrastructure', 'shogunate', 'rickshaw', and 'designate' are just a handful of lexical items that might be unfamiliar to high school students. Not only are they low frequency words in texts (for example, the frequency of 'shogunate' on the Corpus of Contemporary American English database was 21), but their applicability in daily conversation is certainly questionable. While it is opportunity for students to expand their vocabulary, practicality or relevance seems to be an outstanding issue. Given that "expansion of English communication" was listed as one of the major aims of the textbook and project, perhaps more practical vocabulary and functional language would be more appropriate.

\section{Analysis: Relevance of Content}

When considering the relevance of a textbook's content, it is essential to measure the extent to which it meets the original aims of the publisher. In this case, the aims were facilitating understanding of Japanese culture and history, the expansion of English communication, and the promotion of education for international understanding. Basically, students should be able to improve their communicative abilities while both demonstrating knowledge and interest in their own culture as well as others. This is fairly reasonable in theory, but upon inspection of the textbooks, there is a distinct bias towards showcasing Japanese culture and very little mention of other cultures. For example, consider the results obtained from a word frequency analysis of all three texts in the following three figures. 
Figure 2: Intermediate Level Word Frequency

\begin{tabular}{l|l|l|} 
Term & Count & Relative \\
\hline tokyo & 100 & 10,052 \\
\hline people & 64 & 6,433 \\
\hline edo & 56 & 5,629 \\
\hline make & 42 & 4,222 \\
\hline ramen & 41 & 4,121 \\
\hline japan & 39 & 3,920 \\
\hline rakugo & 39 & 3,920 \\
\hline japanese & 37 & 3,719 \\
\hline period & 36 & 3,619 \\
\hline emma & 35 & 3,518 \\
\hline
\end{tabular}

Source: Author's data analysis

Figure 3: Elementary Level Word Frequency Figure 4: Basic Level Word Frequency

\begin{tabular}{l|l|l} 
& Term & Count \\
\hline 1 & let's & 28 \\
\hline 2 & try & 24 \\
\hline 3 & it's & 14 \\
\hline 4 & like & 13 \\
\hline 5 & water & 10 \\
\hline 6 & what's & 10 \\
\hline 7 & fun & 9 \\
\hline 8 & i'm & 9 \\
\hline 9 & tokyo & 8 \\
\hline 10 & want & 8
\end{tabular}

\begin{tabular}{r|l|l} 
& Term & Count \\
\hline 1 & tokyo & 67 \\
\hline 2 & robin & 41 \\
\hline 3 & it's & 39 \\
\hline 4 & japanese & 31 \\
\hline 5 & i'm & 29 \\
6 & fireworks & 28 \\
\hline 7 & look & 27 \\
\hline 8 & think & 27 \\
\hline 9 & sakura & 26 \\
\hline 10 & eco & 24
\end{tabular}

Source: Author's data analysis

Source: Author's data analysis 
Evidently, the terms 'Tokyo', 'Japan', and 'Japanese' are commonly featured across all three textbooks. The frequency of 'It's' seems to suggest the texts are laden with demonstrative language and perhaps focus on "telling" or making suggestions rather than interacting. This is also reinforced in the findings concerning the most frequent three- or four-word phrases used in the textbooks. At the elementary level, 'let's try' and 'let's have' are frequent, while at the basic level, 'are you looking for' and 'tell you about my' are commonly used. Similarly, commonly-used phrases at the intermediate level included 'take a look at' and 'it is said that'.

Granted, while the aim of the textbooks is reflected in title of the series, based on the findings from the corpus analysis and general discourse in the dialogue sections, the Japanese characters in the scenarios lack mutual interest or consideration of diverse cultures. In addition, the foreign characters which appear in the texts are clearly from Anglophone countries. For instance, in the elementary-level textbook, aside from the characters which are explicitly Japanese, the ratio of Caucasian to non-Caucasian figures is $7: 1$, while it evens out in the basic level (1:1). On the other hand, in the intermediate level, the only non-Japanese character which is featured is Caucasianreinforcing the Anglo-centric bias in English language education in Japan and the tendency to place significant value on native-speakerism. Given that most visitors to Japan are from South Korea, China, Taiwan and a growing number of tourists are now visiting from South East Asia (JTB Tourism Research \& Consulting Co., 2018), it would be more reasonable to welcome characters from those regions, too.

Another major concern is the choice of topics. Take, for example, the major topics featured in the basic and intermediate-level textbooks. Although judo, fireworks, Edo-komon, rakugo, flower arrangement and the Ogasawara Islands may be of interest to some visitors, the chances of such topics coming up in daily conversation is questionable. While topics such as table manners, the bus, bento and etiquette seem applicable to situations one is likely to encounter when conversing with visitors from abroad, for the most part, the majority of topics are designed to be "told" or "explained" while the other non-Japanese party listens and almost always expresses astonishment or at least responds positively. Exemplary of such can be found in an excerpt from Topic 5 (Judo) in the basic-level textbook in which the dialogue between Ricky, Robin and Sakura emphasizes the visitor's ignorance (and thereby his need to be taught) and the glorifying of "small people" winning against "big people":

Ricky: Judo is a sport that was born in Japan. It's a really cool sport.

Robin: Tell me more!

Sakura: Well, with good skills, even small people can win against big people.

Robin: You're right! Look at that boy! He's small but very strong. Hmm. Someday I would like to try judo (TMBOE, 2016). 
There is no evidence of debate or negotiation, and the Japanese characters show little to no interest in the guest's culture. Moreover, sometimes the information is heavily biased. For example, the topics about public transportation do not mention the congestion or groping problems and discomfort for train passengers in the morning and the unit on "Eco-friendly Living" does not take into account Japan's continued use of nuclear power even after the March 11 disaster. Simply put, the textbooks lack diversity and balance as well as functional or practical language.

\section{Conclusion}

All things considered, Welcome to Tokyo should ideally be utilized as a supplementary text from which instructors can select topics they deem appropriate or relevant. While the DVDs and images lend the books an approachable image, ease of reading remains an issue and some students may struggle with the texts. Overall, the series would benefit from adding more functional language and omitting topics that are unlikely to come up in daily conversation. The authors could improve the texts by actually focusing on scenarios in which Japanese are most likely to encounter foreigners (such as in convenient stores or in train cars). Moreover, with less bias, greater balance and more diversity in regards to the representation of race and culture, Welcome to Tokyo might actually be more welcoming.

\section{References}

BYRAM, M. (2009) Intercultural competence in Foreign Languages: The intercultural speaker and the pedagogy of foreign language education. In: Deardorff, D.K. (ed.) The Sage Handbook of Intercultural Competence. London, Sage, pp. 321-332.

Japanese Ministry of Education, Culture, Sports, Science, and Technology. (2016) English Education Reform Plan corresponding to Globalization. Available from: http://www.mext.go.jp/english/ [Accessed 19th October 2018].

JTB Tourism Research \& Consulting Co. (2018) Japan-bound Statistics. Available from: https://www.tourism.jp/en/tourism-database/stats/inbound/ [Accessed 22nd October, 2018].

LANGE, E. J., Gorshkov, V., \& Flanagan, B. (2016) Gearing up for the Olympics in English classes. In: P. Clements, A. Krause, \& H. Brown (eds.) Transformation in language education. Tokyo, JALT.

The Mainichi. (2017). 中学英語教員、T O E I C「合格」わずか 疑問も [Concerns rise over junior high school teachers barely passing the TOEIC test]. The Mainichi. [Online]. 11 February 11. [Accessed 20th October 2018]. Available from: https://mainichi.jp/articles/20170211/k00/00e/040/270000c 
PICKLES, M. (2017). Japan turns to Basil Fawlty in race for Olympic English. BBC. [Online]. 29 March. [Accessed 19th October 2018]. Available from:

https://www.bbc.com/news/business-39410915

Tokyo Metropolitan Board of Education. (2016) Welcome to Tokyo. Tokyo, SUN-A Printing.

Tokyo Metropolitan Board of Education. (2018) W to T. Available from: http://tokyo-portaledu.com/wtot.html [Accessed 19th October 2018]. 